\title{
Effect of nutrition and Enteromyxum leei infection on gilthead sea bream Sparus aurata intestinal carbohydrate distribution
}

\author{
Itziar Estensoro ${ }^{1, *}$, María José Redondo ${ }^{1, *}$, Beatriz Salesa1 $^{1}$ Savasidam Kaushik $^{2}$, \\ Jaume Pérez-Sánchez ${ }^{1}$, Ariadna Sitjà-Bobadilla ${ }^{1, * *}$ \\ ${ }^{1}$ Instituto de Acuicultura Torre de la Sal, Consejo Superior de Investigaciones Científicas (IATS-CSIC), Torre la Sal s/n, \\ 12595 Ribera de Cabanes, Castellón, Spain \\ ${ }^{2}$ INRA, UMR1067 NuMeA Nutrition, Metabolism, Aquaculture, 64310 St. Pée-sur-Nivelle, France
}

\begin{abstract}
The effect of a practical plant protein-based diet containing vegetable oils (VO) as the major lipid source on the mucosal carbohydrate pattern of the intestine was studied in gilthead sea bream Sparus aurata challenged with the myxosporean parasite Enteromyxum leei. Fish fed for 9 mo either a fish oil (FO) diet or a blend of VO at $66 \%$ of replacement (66VO diet) were exposed to parasite-contaminated water effluent. Samples of the anterior, middle and posterior intestine (AI, MI and PI, respectively) were obtained for parasite diagnosis and histochemistry. Fish were categorised as control (C, not exposed), early (E) or late (L) infected. Mucin and lectin histochemistry was applied to detect the different types of mucins and sialic acid in goblet cells (GC), the brush border and enterocytes. The number of GC stained with periodic acid Schiff (PAS), alcian blue (AB), aldehyde fuchsin-alcian blue (AF-AB), for the detection of neutral, acidic, sulphated and carboxylic mucins, and with the lectin Sambucus nigra agglutinin (SNA), were counted in digital images. The 66VO diet produced a significant decrease of GC with neutral and acidic mucins in the AI and MI, and also of those with carboxylic mucins and sialic acid in the MI. Sulphated mucins and sialic acid were less abundant in the AI than in the MI and PI in the C$66 \mathrm{VO}$ treatment. E. leei infection had a strong effect on the number of GC, as E and L infected fish had a significant decrease of GC positive for all the stains versus $C$ fish in PI. Time and diet effects were also observed, since the lowest values were mostly registered in E-66VO fish in PI. In conclusion, though GC depletion was mainly induced by enteromyxosis, an effect of the diet was also observed. Thus, the diet can be a predisposing factor that worsens the disease course.
\end{abstract}

KEY WORDS: Goblet cell · Replacement diet - Parasite - Myxozoa - Myxosporea · Mucin · Histochemistry $\cdot$ Lectin

\section{INTRODUCTION}

Intensive farming practices favour the emergence of infectious diseases, posing a major problem in aquaculture industry, and these practices are likely to select for fast-growing, early-transmitted, and hence probably more virulent parasites (Mennerat et al. 2010). Parasites such as sea lice (Costello 2009), myxosporeans (Kent et al. 1994, Moran et al. 1999,
Ferguson et al. 2011, Okamura \& Feist 2011) or Cryptobia salmositica (Woo 2003) account for massive losses in fish culture. Fishborne zoonotic parasites are also acquiring worldwide relevance in aquaculture (Lima dos Santos \& Howgate 2011). In the Mediterranean basin, gilthead sea bream Sparus aurata is the main cultured fish species, with a total production of more than $130000 \mathrm{t}$ in 2010 (APROMAR 2011), and Enteromyxum leei is one of its threatening parasitic 
diseases (Palenzuela 2006). This parasite invades the intestine of gilthead sea bream, producing a slow-progressing disease, which induces anorexia, cachexia and eventually death. Its impact is further enhanced due to its direct fish-to-fish transmission (reviewed in Sitjà-Bobadilla et al. 2007). Thus far, there are neither preventive nor curative treatments for this enteromyxosis. Therefore, there is an urgent need to advance the knowledge of the parasite invasion mechanisms and the host-parasite interaction.

The increased consumer demand for healthy, safe and high quality fish products together with the need to reduce the cost of fish feeds and the dependency on fisheries to produce aquafeeds (Tacon \& Metian 2008) has led to the substitution of fish meal (FM) and fish oil (FO) by optimised levels of vegetables. The possible effects of such alternative diets have to be approached in an integrative manner, and therefore growth performance and animal health and welfare have to be studied altogether. Previous works on gilthead sea bream have demonstrated that FO can be replaced by a mixture of vegetable oils with up to $66 \%$ plant-protein based diets (66VO) without detrimental effects on growth, redox balance, immunocompetence or on the intestinal and hepatic architecture (Benedito-Palos et al. 2007, 2008, 2009, Saera-Vila et al. 2009). However, when 66VO fish were challenged with Enteromyxum leei, the disease outcome was greater than in FO-fed animals (Estensoro et al. 2011a).

In an effort to understand the possible underlying mechanisms involved in the worse progression of the infection in $66 \mathrm{VO}$ fish, we have started a series of detailed studies of the gut immunology and architecture in both diet groups. The current study is focused on the carbohydrate features of the mucus layer of the intestinal tract because the previous information on Enteromyxum scophthalmi and E. leei suggests a role of some carbohydrate moieties in the interaction with their hosts (Redondo et al. 2008, Redondo \& Alvarez-Pellitero 2009). The mucosal surface of the gastrointestinal tract is a complex organisation of epithelium, immune cells and resident microbiota (McCracken \& Lorenz 2001, Rombout et al. 2011). The intestinal epithelium is covered by a mucus layer, with mucins acting as the main structural component. Mucins are secreted by goblet cells (GC) and are mainly found at the periphery of epithelial cells and their extracellular environment or covering epithelial cells. Thus, they form a mesh-like structure that impedes the diffusion of offending macromolecules, constituting an immune defence barrier (Dharmani et al. 2009). Pathogens generally initiate in- fection by the specific recognition of host epithelia surfaces. Receptors present in the mucin layer can act as binding sites in the subsequent adhesion, which is essential for invasion. In their infection strategy, pathogens often use sugar-binding proteins, such as lectins and adhesins, to recognise and bind to host glycoconjugates where sialilated and fucosylated oligosaccharides are the major targets. In addition, microbial products can alter the production of mucins and many enteric microbes and their toxins are known to have a potent secretagogue effect on GC in mammalian models. This rapid mucin secretion can be an important mechanism of protection by eliminating the pathogens. By contrast, other pathogens induce mucus depletion, producing deleterious side effects (Moncada et al. 2003, Linden et al. 2008).

Changes in the number of GC cells as a consequence of infection have been reported in several fish-parasite models (Fleurance et al. 2008, Bermúdez et al. 2009) and qualitative or semi-quantitative analyses have been done in Enteromyxum leei-infected gilthead sea bream (Fleurance et al. 2008, Redondo \& Alvarez-Pellitero 2010b), but no quantitative kinetic study with a high number of fish is available. Furthermore, there is no information on the effect of the diet on mucins and terminal carbohydrate residues in the intestinal mucosa of gilthead sea bream. For such purpose, in the present work, histochemistry and lectin histochemistry were applied to study the changes induced by $E$. leei infection at different times of infection and by long-term feeding with a diet with high levels of plant protein and oil sources.

\section{MATERIALS AND METHODS}

\section{Experimental set up and sample collection}

Gilthead sea bream were fed for 9 mo either a FO diet or a blend of $\mathrm{VO}$ at $66 \%$ of replacement (66VO diet) until they reached an average initial mean weight of $224 \mathrm{~g}$ (age = $15 \mathrm{mo}$ ). They were then allocated to 2 control (C) tanks and 2 recipient (R) tanks ( 1 for each dietary treatment). $\mathrm{R}$ fish were challenged by exposure to Enteromyxum leei-contaminated effluent as previously described (Sitjà-Bobadilla et al. 2007). Briefly, $R$ tanks ( $n=30$ fish $\operatorname{tank}^{-1}$ ) were set to exclusively receive the effluent water from another tank containing infected fish, whereas $\mathrm{C}$ tanks $(\mathrm{n}=30$ fish $\operatorname{tank}^{-1}$ ) were kept under the same conditions but without receiving $E$. leei-contaminated water. In both groups ( $\mathrm{C}$ and $\mathrm{R}$ ), fish were kept in $5 \mu \mathrm{m}$ filtered and UV-irradiated sea water (37.5\% salinity) at a mean 
temperature of $21.3 \pm 0.25^{\circ} \mathrm{C}$ (range $=18.5$ to $26^{\circ} \mathrm{C}$ ). All fish were individually tagged with passive integrated transponders and were non-lethally sampled periodically by probing their rectums with a cotton swab. Non-lethal PCR diagnosis was carried out to ascertain their infection status as described in Palenzuela \& Bartholomew (2002), with primers specific for E. leei rDNA. This procedure has been validated against a gold standard (histological observation of the whole digestive tract), and resulted in a high sensitivity (0.96) and specificity (1) (O. Palenzuela unpubl. data). After $102 \mathrm{~d}$ post exposure (dpe), 10 fish from each $\mathrm{C}$ group and 15 fish from each $\mathrm{R}$ group were euthanised under anesthesia (3-aminobenzoic acid ethyl ester, $100 \mathrm{mg} \mathrm{l}^{-1}$ ) (Sigma), and samples of anterior, middle and posterior intestine (AI, MI and PI, respectively) were taken for histochemistry. For more details see Estensoro et al. (2011a).

$\mathrm{R}$ fish were classified in 2 categories: parasitised at early (E) or late (L) times of infection after exposure, which were compared with $\mathrm{C}$ animals (not exposed to the parasite). As the final prevalence of infection was high in both groups (84 and $96.2 \%$ in FO and $66 \mathrm{VO}$ fish, respectively), the number of non-parasitised fish was very low and not statistically useful to be included in the analysis. Fish from the E group were infected at 32 or 53 dpe and had high intensity of infection in several intestinal sections, whereas L fish were infected just 1 sampling before the end of the experiment ( $88 \mathrm{dpe}$ ) and had low infection levels in $\mathrm{AI}$ and $\mathrm{MI}$ in most cases. The mean intensity of infection was high at the PI in both diet groups but was clearly higher at the AI and MI in R-66VO fish than in R-FO ones. See Estensoro et al. (2011a) for more details.

All the experiments were carried out according to national (Royal Decrete RD1201/2005, for the protection of animals used in scientific experiments) and institutional regulations (CSIC, IATS Review Board) and the current European Union legislation on handling experimental animals.

\section{Mucin and lectin histochemistry}

Pieces of the AI, MI and PI intestine were fixed in $10 \%$ buffered formalin, embedded in paraffin, $4 \mu \mathrm{m}$ sectioned and stained using the following histochemical techniques: periodic acid Schiff (PAS) to demonstrate neutral mucins (magenta-stained); alcian blue (AB) recognising predominantly acidic mucins (bluestained); and aldehyde fuchsin-AB (AF-AB) for localisation of the sulphated (purple-stained) and/or car- boxylic type (blue-stained) of acidic mucins. For the detection of $\mathrm{N}$-acetylneuraminic acid ( $\alpha 2$ 2-6)galactose and $\mathrm{N}$-acetylneuraminic acid ( $\alpha 2-6)$ - $\mathrm{N}$-acetylD-galactosamine (= sialic acid), paraffin sections were collected on Super Frost-plus microscope slides (Menzel-Glaser) without additives and allowed to dry overnight. We chose to detect sialic acid because this terminal carbohydrate residue was previously shown to be modulated by enteromyxosis in gilthead sea bream intestine (Redondo \& Alvarez-Pellitero 2010a).

Slides were deparaffinised and hydrated, and the endogenous peroxidase activity was blocked by incubation in hydrogen peroxide $(0.3 \% \mathrm{v} / \mathrm{v}$ for $30 \mathrm{~min})$. After rinsing with Tris-buffered saline containing $0.05 \%$ Tween 20 (TTBS, $20 \mathrm{mM}$ Tris- $\mathrm{HCl}, 0.5 \mathrm{M} \mathrm{NaCl}$ $\mathrm{pH}$ 7.2), sections were incubated with the biotinylated lectin Sambucus nigra agglutinin (SNA) (Sigma) solution $\left(20 \mu \mathrm{g} \mathrm{ml}^{-1}\right)$ in TTBS for $1 \mathrm{~h}$ at $20^{\circ} \mathrm{C}$. After rinsing, the sections were incubated with the avidin-biotinperoxidase complex (ABC, Vector Laboratories) for $30 \mathrm{~min}$ at $20^{\circ} \mathrm{C}$ and bound peroxidase was finally revealed by adding DAB chromogen (3,3'-diaminobenzidine tetrahydrochloride) (Sigma) for $5 \mathrm{~min}$. The reaction was stopped with deionised water, and the sections counterstained using Gill's haematoxylin and finally mounted in di-N-butyl-phthalate in xylene (DPX). Adequate controls were included as described in Redondo \& Alvarez-Pellitero (2010a).

For each fish, intestinal section and staining, 10 microscope fields at $25 \times$ were digitally photographed and the number of positive goblet cells (GC) for each staining was counted using Photoshop's (Adobe Systems) count tool. Thus, for each staining technique, 1500 images were processed. The mean and SEM of each group was calculated. In addition, for SNA lectin, a semiquantitative evaluation of the staining intensity in the brush border (BB) and the epithelial layer was performed. The staining intensities were evaluated on a scale of 0 to $6(0=$ no staining; $1=$ very weak; $2=$ weak; $3=$ moderate; $4=$ strong; $5=$ very strong, $6=$ strongest).

\section{Statistics}

For each intestinal section and diet, differences between the 3 infection categories $(C, L, E)$ were analysed by 1 -way analysis of variance (ANOVA-I) followed by Student-Newman-Keuls test. When the tests of normality or equal variance failed, a KruskalWallis 1-way ANOVA on ranks followed by Dunn's method was applied instead. The same test was 
applied to determine possible differences between C fish along the 3 intestinal sections, each diet group separately. A Student's t-test was used to analyse the differences between both diet groups in each intestinal section and infection category. A 3-way ANOVA (ANOVA-III) was used to globally analyse the effect of the 3 factors involved in the presence of carbohydrates: the intestinal section, the time of infection and the diet. As the intensity of infection seemed to gather the effect of the 3 factors previously analysed, the strength of its possible association with the number of GC positive for each stain in individual fish was measured with a Spearman rank order correlation test (since the normality test failed for some of them) collating all the data of the 3 intestinal sections from all the diet groups. When significant correlations were found, additional ANOVA-I tests were performed to establish the differences between the different intensity of infections. All the statistical analyses were performed using Sigma Stat software (SPSS) and the significance level was set at $\mathrm{p}<0.05$.

\section{RESULTS}

\section{Mucin histochemistry}

Neutral mucins, as revealed by PAS staining, were similarly abundant in GC at the 3 intestinal sections among $\mathrm{C}$ animals, as no differences along the sections were observed in either of the diet groups (Figs. 1A $\& 2)$. However, $\mathrm{C}$ animals fed the 66VO diet had a significantly lower $(\mathrm{p}<0.05)$ number of PAS+ GC than CFO fish in the AI and MI. No diet effect was detected in the PI in C fish. The infection also had a clear effect, as early (E) and late (L) infected R fish had significantly lower numbers of GC than $\mathrm{C}$ fish, regardless of the intestinal section in the FO fed group, whilst in the $66 \mathrm{VO}$ group this difference was only statistically significant in the PI section. However, a clear decreasing trend was observed with the time of infection, and the lowest value was found in the PI of E infected fish fed the 66VO diet (Figs. 1A \& 2).

Acidic mucins, stained by alcian blue (AB), were also abundant in GC in the 3 intestinal sections, and their distribution showed a pattern similar to that observed for neutral mucins, with no differences among $\mathrm{C}$ fish along the intestinal tract in any of the diet groups (Figs. 1B \& 3). C-66VO animals also had a significantly lower $(p<0.001)$ number of $A B+G C$ at $\mathrm{AI}$ and $\mathrm{MI}$ than $\mathrm{C}-\mathrm{FO}$ fish. R-infected fish (both $\mathrm{E}$ and L) had significantly lower values than $C$ fish in the PI, regardless of the diet group, but only for FO group in the MI. Again, the lowest count was registered in the PI of E-R-66VO fish (Figs. 1B \& 3).

The AF-AB staining allowed a detailed analysis of the acidic mucin types present in GC. As shown in Figs. 4 \& 5, most of them were carboxylic, followed by mixed and sulphated. Carboxylic mucins presented a similar pattern of distribution in $\mathrm{C}$ animals in both diet groups, but a statistically significant decrease of carboxylic GC was detected in $\mathrm{C}$ fish fed the 66VO diet compared to C-FO group in the MI. Similarly to acidic mucins, E- and L-R infected fish had significantly lower values than $\mathrm{C}$ fish in the PI in the R-66VO
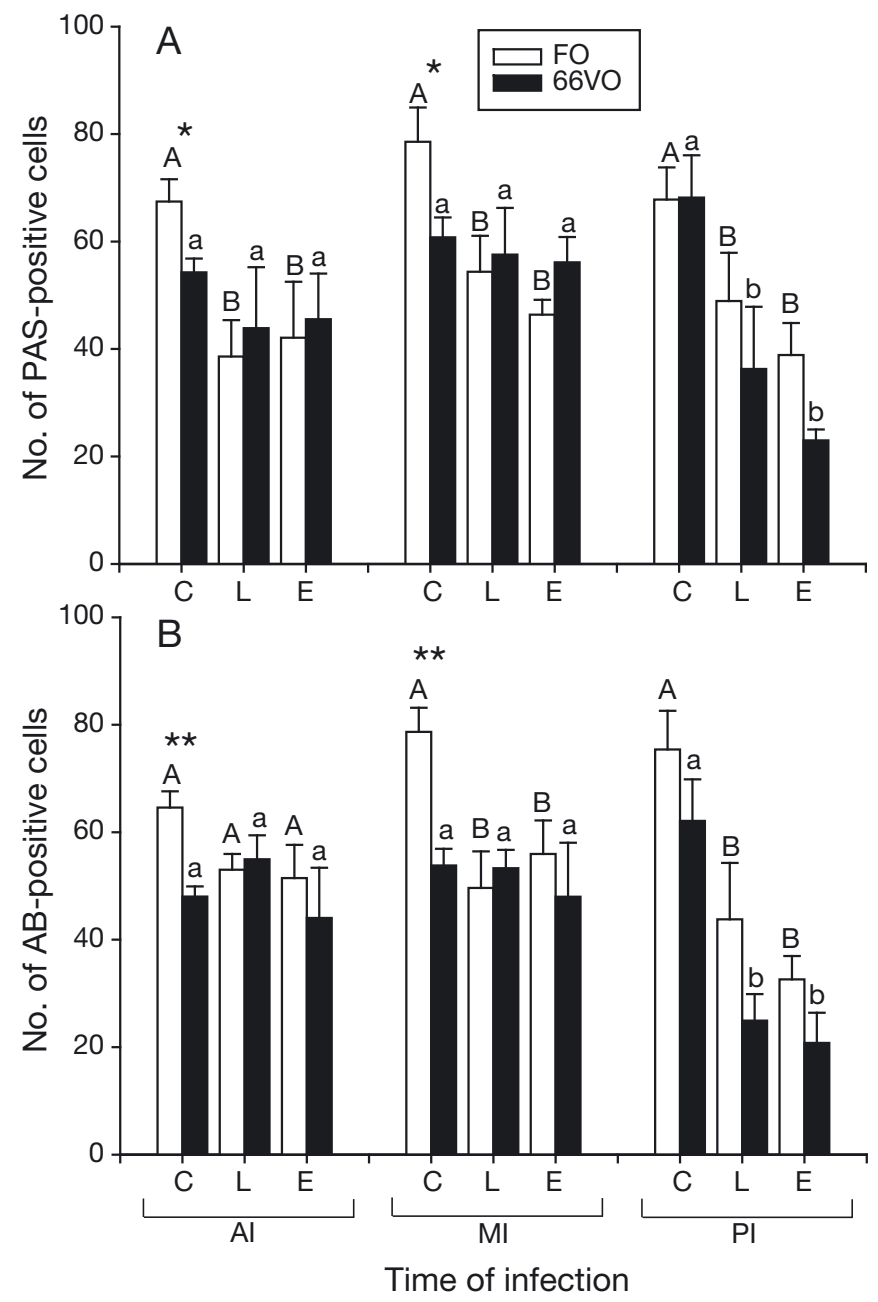

Fig. 1. Enteromyxum leei infecting Sparus aurata. Number (average + SEM) of goblet cells (GC) containing (A) periodic acid Schiff positive (PAS+) neutral mucins or (B) alcian blue positive $(\mathrm{AB}+)$ acidic mucins in the anterior $(\mathrm{AI})$, middle $(\mathrm{MI})$ and posterior (PI) intestine sections for control (C), late infected (L) and early infected (E) fish. Different letters indicate significant differences $(p<0.05)$ between time of infection groups within the fish oil (FO) diet (uppercase letters) and within the vegetable oil (66VO) diet (lowercase letters). Asterisks indicate significant differences between diet groups: ${ }^{*} \mathrm{p}<0.05,{ }^{* *} \mathrm{p}<0.001$ 


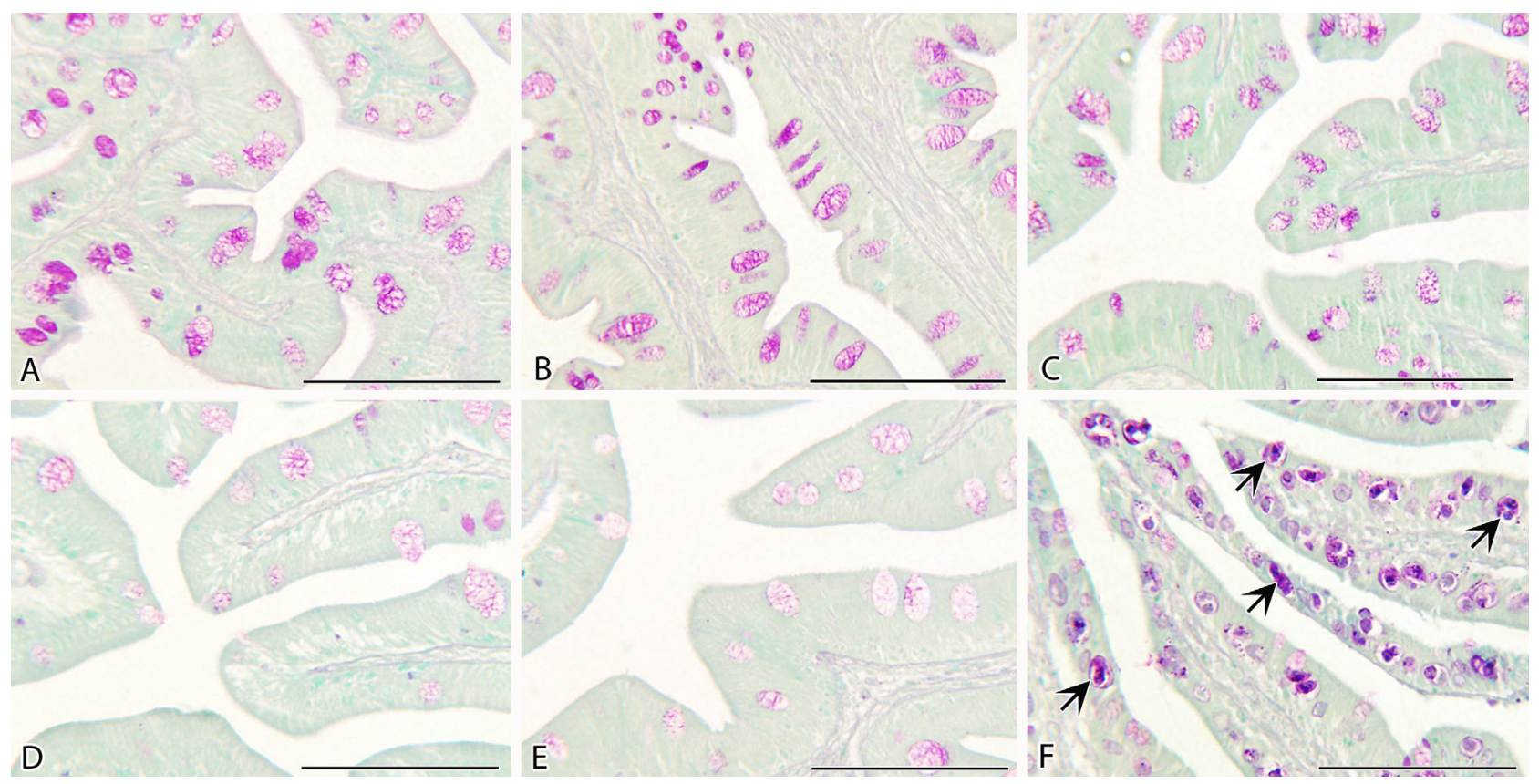

Fig. 2. Enteromyxum leei infecting Sparus aurata. Photomicrographs of gilthead sea bream intestines in paraffin sections stained with periodic acid Schiff (PAS). Neutral mucins contained in epithelial goblet cells and PAS+ structures are stained magenta. (A-C) Control, unexposed fish fed the fish oil (FO) diet: (A) anterior, (B) middle and (C) posterior intestines. (D-F) Fish fed the vegetable oil (66VO) replacement diet: (D) anterior intestine of a control fish, (E) middle intestine of a control fish and $(\mathrm{F})$ posterior intestine of an early infected recipient fish. Arrows: Dark stained PAS+ structures in Enteromyxum leei stages. Scale bars $=100 \mu \mathrm{m}$
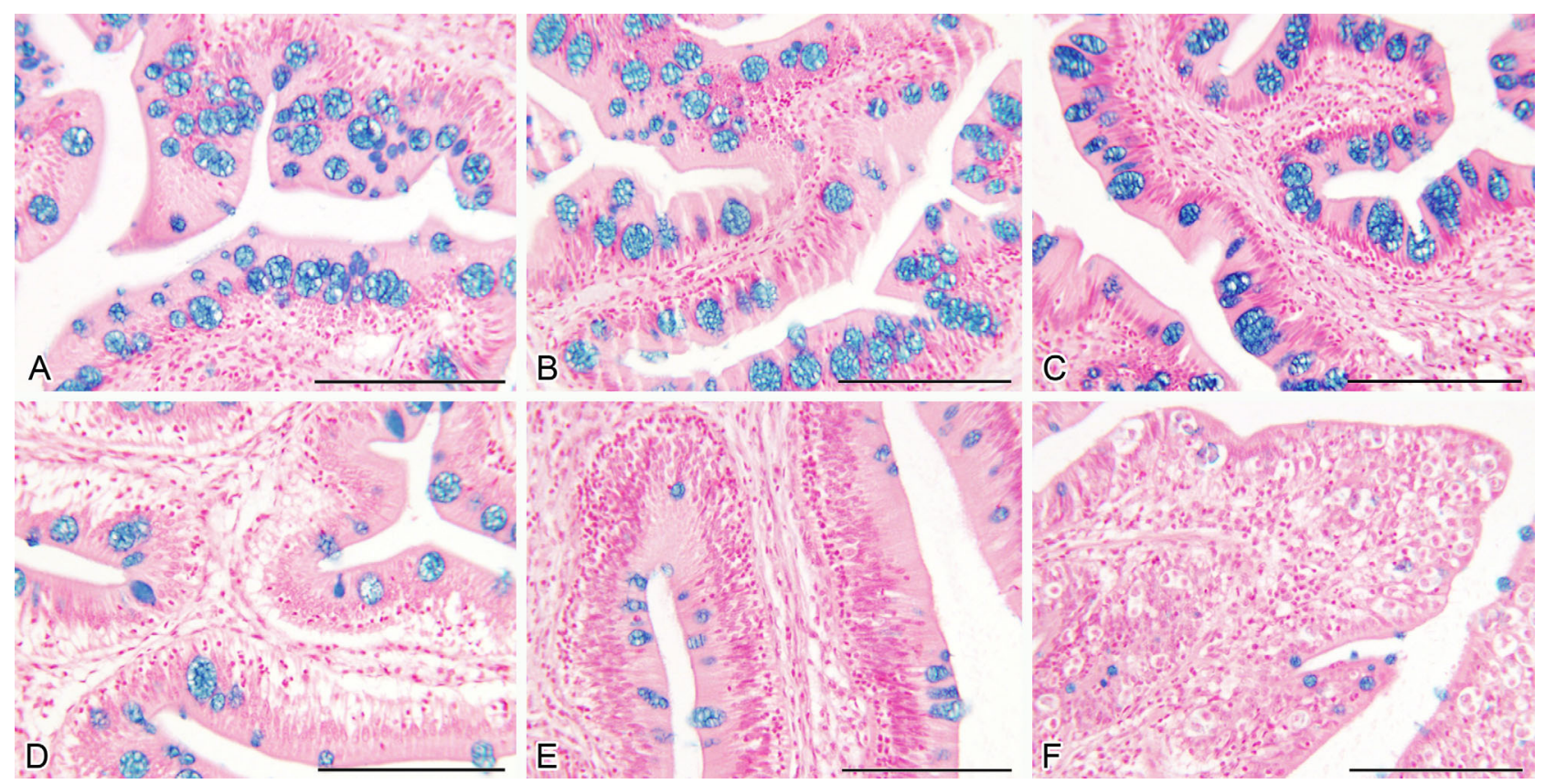

Fig. 3. Enteromyxum leei infecting Sparus aurata. Photomicrographs of gilthead sea bream intestines in paraffin sections stained with alcian blue (AB). Acidic mucins contained in goblet cells are stained blue. (A-C) Control, unexposed fish fed the fish oil (FO) diet: (A) anterior, (B) middle and (C) posterior intestines. (D-F) Fish fed the vegetable oil (66VO) replacement diet: (D) anterior intestine of a control fish, (E) middle intestine of a control fish and (F) posterior intestine of an early infected recipient fish. Scale bars $=100 \mu \mathrm{m}$ 

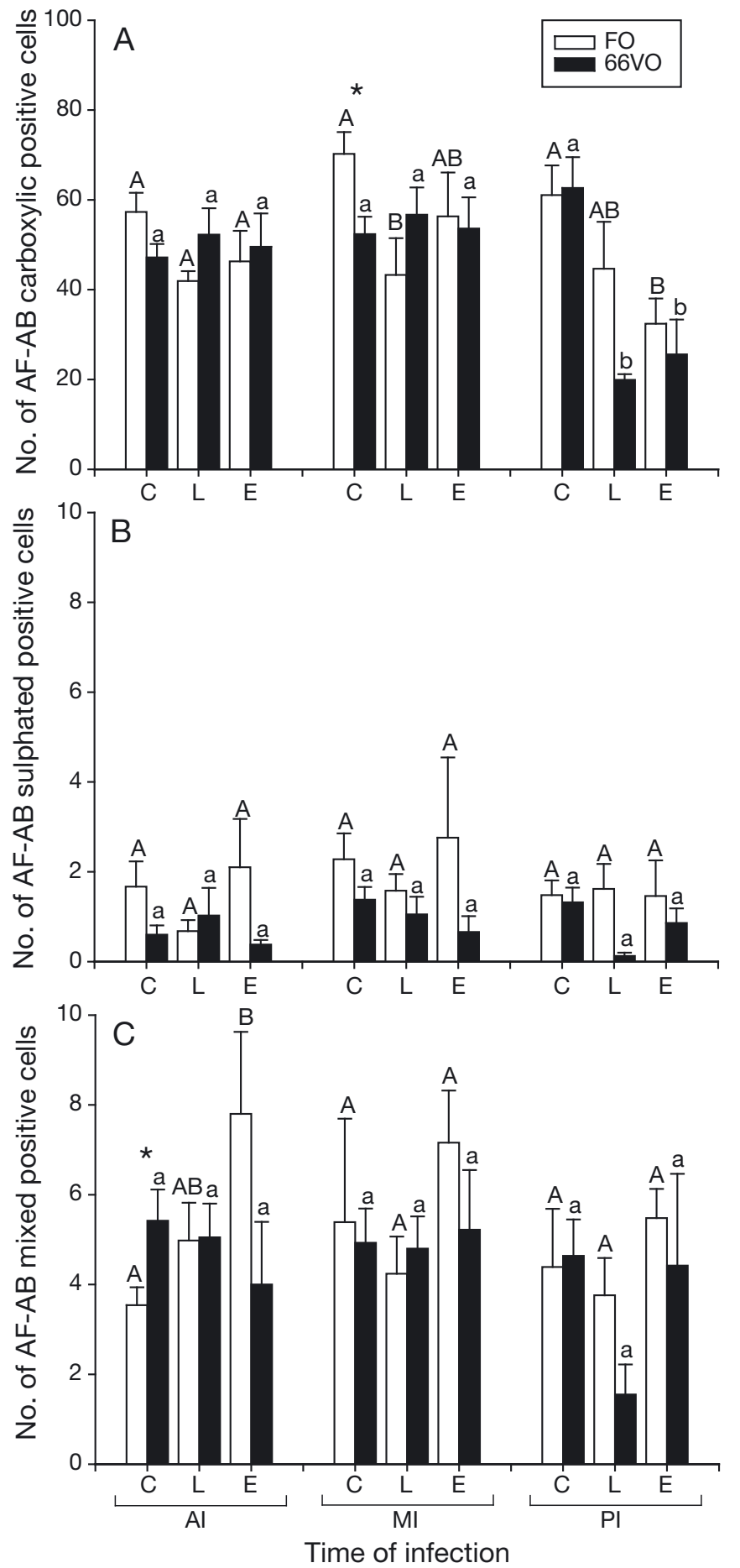

Fig. 4. Enteromyxum leei infecting Sparus aurata. Number (average + SEM) of aldehyde fuchsin-alcian blue positive $(\mathrm{AF}-\mathrm{AB}+)$ goblet cells (GC) containing (A) carboxylic, (B) sulphated or (C) mixed sulphated-carboxylic mucins in the anterior (AI), middle (MI) and posterior (PI) intestine sections for control (C), late infected (L) and early infected (E) fish. Different letters indicate significant differences $(\mathrm{p}<$ 0.05) between time of infection groups within the fish oil (FO) diet (uppercase) and within the vegetable oil (66VO) diet (lowercase letters). Asterisks indicate significant differences between diet groups: ${ }^{*} \mathrm{p}<0.05$ group, whereas only E-R-FO fish had a significant decrease in this section. At MI, L-R-FO fish also had significantly lower values than C fish (Figs. 4 \& 5).

Sulphated mucins were present in small amounts in the 3 intestinal sections. No statistically significant differences were detected in most comparisons, except that C-66VO fish had significantly lower values in the AI than in the MI and PI (Fig. 4B). The pattern of distribution of mixed carboxylic-sulphated GC differed from those of other stains, as only at AI, C-66VO fish had significantly higher values than C-FO ones, and E-R fish from the FO group had significantly higher values than their corresponding $\mathrm{C}$ group (Fig. 4C). No differences were found among the 3 intestinal sections in $\mathrm{C}$ animals of both diet groups.

Hardly any mucin staining was observed on the brush border and no staining was detected in enterocytes with the above techniques applied. Among acidic mucins, a size gradient was observed in positive $\mathrm{GC}_{i}$ carboxylic-GC+ were larger than mixed ones, and sulphated the smallest of the three. In addition, in most parasitised sections, GC appeared smaller than in $\mathrm{C}$ ones (Figs. 3F \& 5F).

\section{Lectin histochemistry}

Sialic acid was detected with the SNA lectin in GC, the $\mathrm{BB}$ and the enterocytes in the 3 intestinal sections, though with clear differences among them. In $\mathrm{C}-66 \mathrm{VO}$ fish, the values obtained in the AI were significantly lower than those of MI and PI, and the number of SNA+ GC at MI was significantly lower than that in C-FO fish (Figs. 6 \& 7). The infection produced a significant decrease of SNA+ GC at PI both in E- and L-R fish regardless of the diet group, but only in the FO group at the MI. Again the lowest value was for the PI of E-R-66VO (Figs. 6 \& 7).

The intensity of staining for sialic acid in BB and the apical part of enterocytes was significantly lower at AI than at MI and PI, regardless of the diet, and no differences were observed between diet groups within each intestinal section (Figs. 6 \& 7). The infection significantly reduced the staining intensity of the $\mathrm{BB}$ in E-R-FO at MI and AI (Fig. 6) and that of the apical enterocyte layer in E- and L-R-66VO in the PI (Fig. 6).

\section{Meta-analysis of the factors affecting carbohydrate distribution}

The ANOVA-III allowed a global and complex analysis of the relationship between the 3 studied 

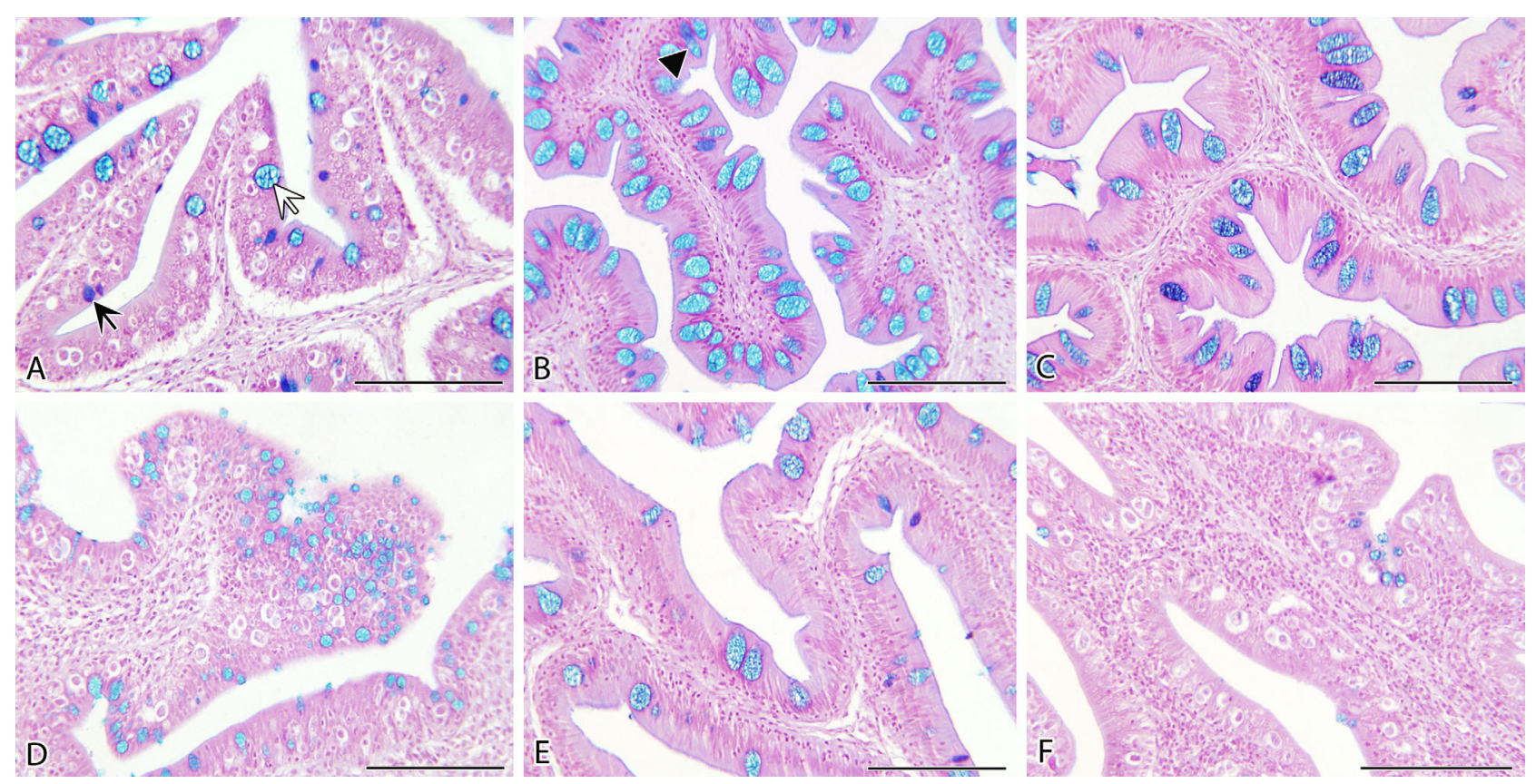

Fig. 5. Enteromyxum leei infecting Sparus aurata. Photomicrographs of gilthead sea bream intestines in paraffin sections stained with aldehyde fuchsin-alcian blue (AF-AB). Carboxylic, sulphated and mixed carboxylic-sulphated acidic mucins contained in goblet cells are stained (white arrow) blue, (black arrow) purple or (black triangle) blue-purple, respectively. (A-C) Fish fed the fish oil (FO) diet: (A) anterior intestine of an early infected recipient fish, (B) middle intestine of a control fish and (C) posterior intestine of a control fish. (D-F) Fish fed the vegetable oil (66VO) replacement diet: (D) anterior intestine of an early infected fish, (E) middle intestine of a control fish and (F) posterior intestine of an early infected fish. Scale bars $=100 \mu \mathrm{m}$

factors involved in mucin presence: diet, time of infection and intestinal section. Table 1 summarises the significance of these 3 factors for each of the applied stains. Intestinal section resulted in an effect in 5 out of the 7 staining patterns analysed, but it only explained up to $8.46 \%$ of the total data variance. When trying to isolate which group differed from the others, in acidic and carboxylic mucins, PI had significantly lower values than $\mathrm{AI}$ and $\mathrm{MI}$, whereas for sialic acid in BB and enterocytes, AI values were significantly lower than those of MI and PI. Time of infection was a strong factor with statistical significance in 5 out of 7 staining patterns, and in most cases it was due to the lower values of E- and Linfected fish versus $\mathrm{C}$ animals. It was the strongest factor, as it explained up to $26.08 \%$ of the total data variance, and p-values were $<0.001$ in all cases. Diet accounted for the global significant differences only for acidic and sulphated mucins, and it explained up to $8.42 \%$ of the total data variance. Significant differences between diet groups were due to the lower values of $66 \mathrm{VO}$. As can be seen in Table 1, there were also significant interactions between the different combinations of 3 factors for several stains; the effect of different levels of a given factor depended on what level of another factor was present. The most com- mon interaction was between infection time and intestinal section. No significant interaction was found between diet and time of infection, and diet and intestinal section. However, triple interactions were significant for carboxylic mucins and sialic acid found in $\mathrm{GC}$, the former explaining $7 \%$ of total data variance.

Intensity of infection was correlated negatively with the number of GC+ for neutral, acidic, carboxylic mucins and sialic acid $(\mathrm{p}<0.0001)$, being the strongest correlation with sialic acid $\left(\mathrm{r}_{\mathrm{S}}=-0.548\right)$ (Fig. 8). The intestinal sections with the highest intensity of infection had the lowest GC+ counts for neutral, acidic, carboxylic mucins and sialic acid, and differed significantly from sections of $\mathrm{C}$ fish and even from non-infected sections of R-fish except for neutral mucins (Fig. 8).

\section{DISCUSSION}

There is a growing interest in formulating diets with low levels of marine ingredients that are still capable of promoting the growth and health of farmed fish. The response to such plant-ingredient based fish diets is still far from being completed, 

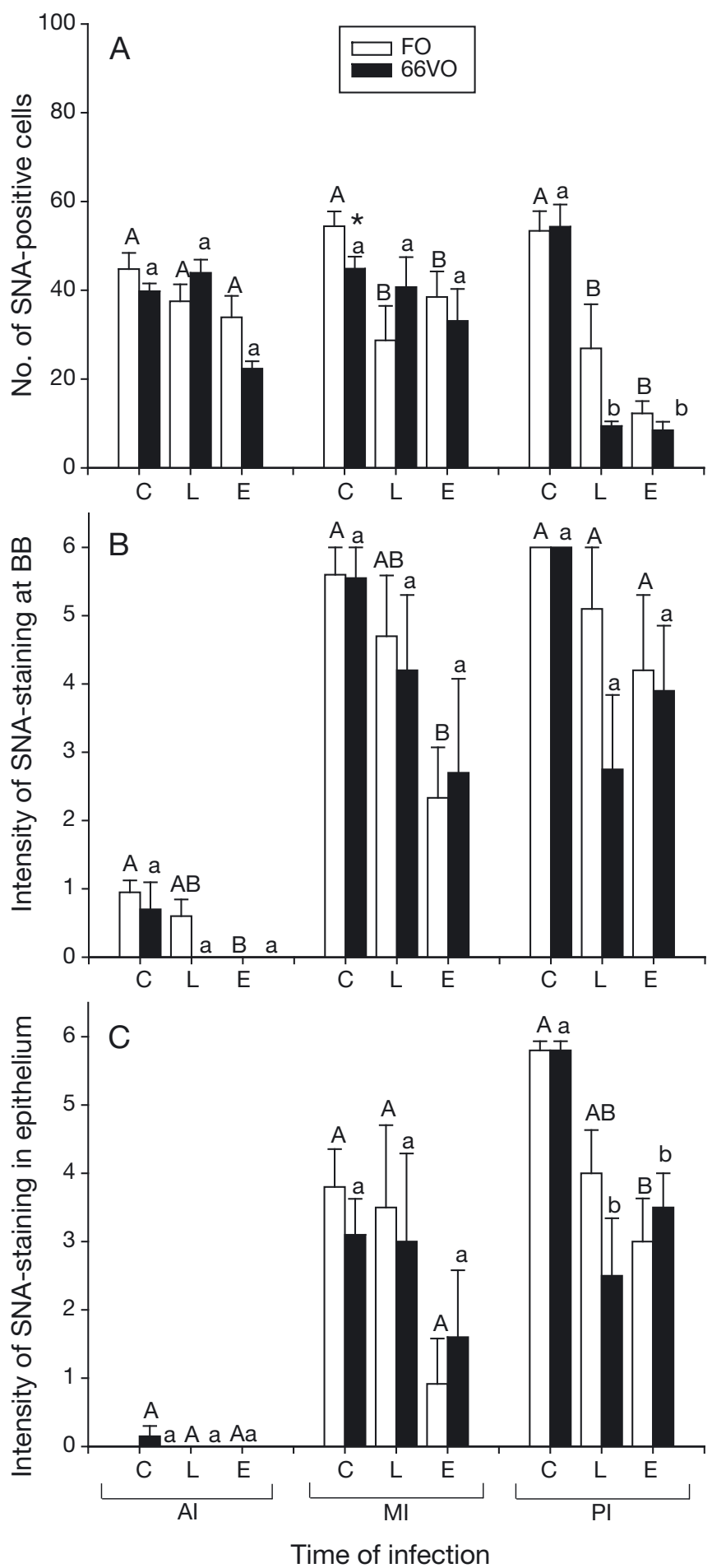

Fig. 6. Enteromyxum leei infecting Sparus aurata. Number (average + SEM) of Sambucus nigra agglutinin positive (SNA+) staining for sialic acid in (A) goblet cells (GC), (B) brush border $(\mathrm{BB})$, or $(\mathrm{C})$ the epithelium in the anterior $(\mathrm{AI})$, middle (MI) and posterior (PI) intestine sections for control $(C)$, late infected (L) and early infected (E) fish. Different letters indicate significant differences $(p<0.05)$ between time of infection groups within the fish oil (FO) diet (uppercase letters) and within the vegetable oil (66VO) diet (lowercase letters). Asterisks indicate significant differences between

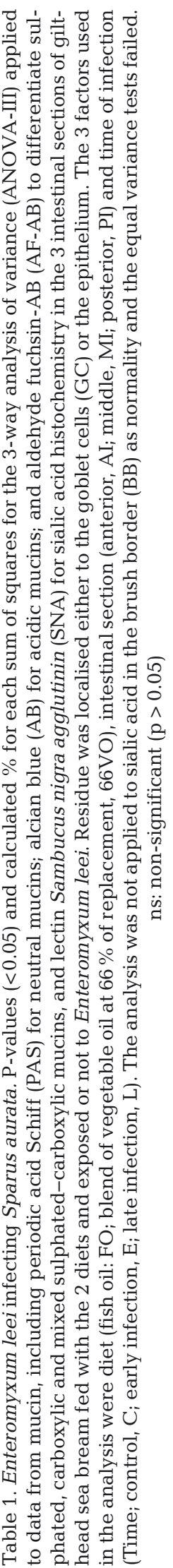



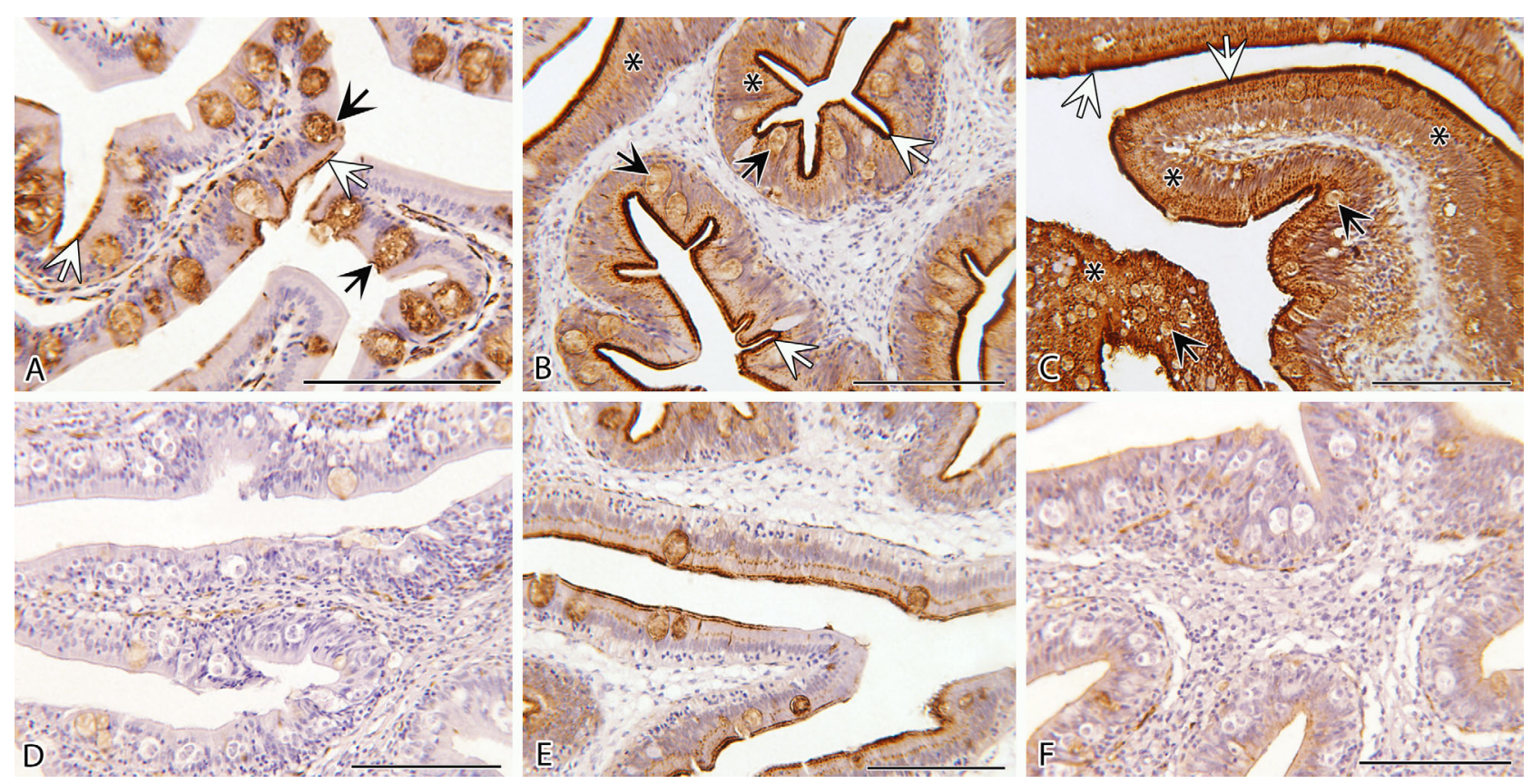

Fig. 7. Enteromyxum leei infecting Sparus aurata. Photomicrographs of gilthead sea bream intestines in paraffin sections stained with the biotinylated lectin Sambucus nigra agglutinin (SNA). Lectin-labeled sialic acid contained in (black arrow) goblet cells, $\left({ }^{*}\right)$ the enterocytes and (white arrow) the brush border appears brown in colour. (A-C) Control, unexposed fish: (A) anterior intestine of a fish fed the fish oil (FO) diet, (B) middle intestine of a FO fish and (C) posterior intestine of a vegetable based diet (66VO) fish. (D) Anterior intestine of an early infected FO fish. (E) Middle intestine of a control 66VO fish. (F) Posterior intestine of a late infected 66VO fish. Note the decrease of SNA labeling in parasitised sections (C, F) and in the middle intestine of control 66VO (E). Scale bars $=100 \mu \mathrm{m}$

especially with regard to health aspects (reviewed in Harikrishnan et al. 2011, Tacchi et al. 2011). The present study was focused on one aspect of gut health, the mucin pattern of the intestine of gilthead sea bream, because of the importance of mucins in many disease processes in which the interaction of epithelial cells and their surroundings has been altered (Gendler \& Spicer 1995, Perez-Vilar \& Hill 1999). Mucins are large, abundant, filamentous, highly glycosylated glycoproteins that consist of $80 \%$ carbohydrates, primarily N-acetylgalactosamine, $\mathrm{N}$-acetylglucosamine, fucose, galactose, and sialic acid ( $\mathrm{N}$-acetylneuraminic acid) and traces of mannose and sulfate. Mucins are present in the piscine intestine very early in larval development (Leknes 2011), during which they may be involved in absorption and transport of macromolecules (Stroband et al. 1979) and may also exert an osmotic function, especially in marine species (Smith 1989). The glycoconjugate composition of mucous secretion in fish is remarkably different among species, and intraspecific (Domeneghini et al. 1998, Sarasquete et al. 2001) and age (Domeneghini et al. 1998, Parillo et al. 2002, Soffientino et al. 2006) variations also occur.
We have shown the effect of both the diet and Enteromyxum leei infection on the carbohydrate pattern of the intestine of gilthead sea bream. First, in C fish (those not exposed to the parasite), the 66VO diet produced a significant decrease of GC with neutral and acidic mucins at $\mathrm{AI}$ and $\mathrm{MI}$ and also of those with carboxylic mucins and sialic acid at MI. Remarkably, depletion effects were found in the intestinal sections that become infected later during the progression of the infection, and these sections had higher prevalence and intensity of infection in R-66VO fish than in FO ones (Estensoro et al. 2011a). There is a general consensus that acidic mucins, such as sialomucin and sulfomucin, play an important role in the protection of mucosa from infectious agents. This is illustrated by Strongyloides venezuelensis infections, in which sulphated glycoconjugates prevent the mucosal invasion by this nematode (Maruyama et al. 2000, 2002). Therefore, the suggestion that the higher levels of GC with such mucins in FO gilthead sea bream could somehow protect these intestinal sections from parasite invasion, or at least delay its entrance, is tempting.

Feeding habits seem to be correlated with the pattern of glycoconjugate glycosylation in different cyprinid fish (Fiertak \& Kilarski 2002). However, 


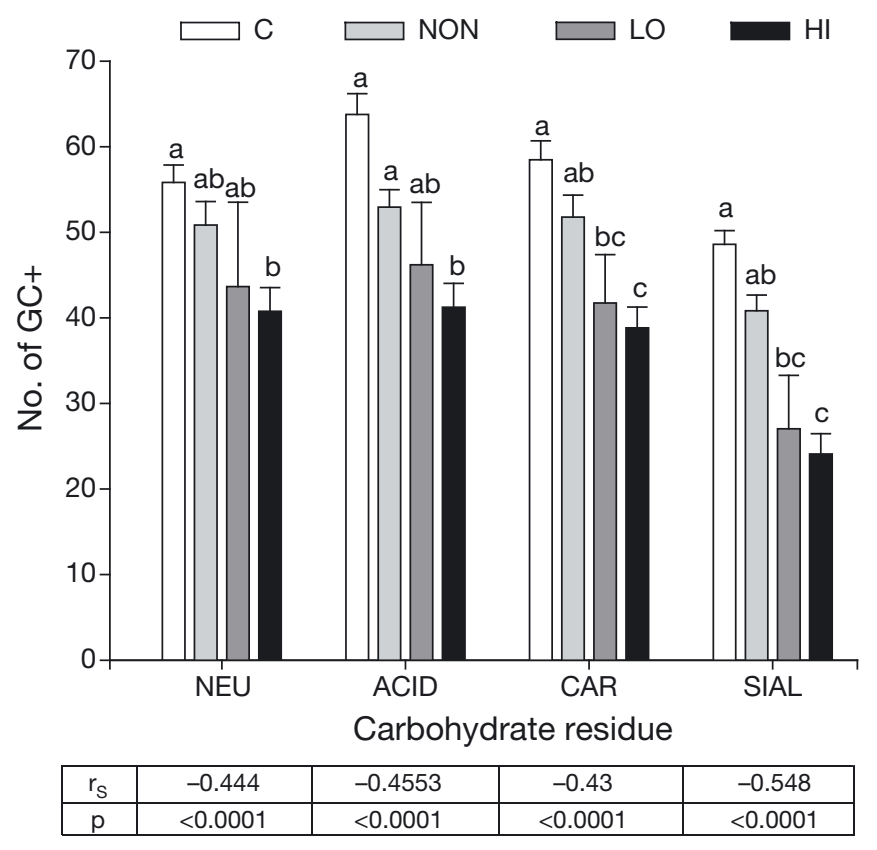

Fig. 8. Enteromyxum leei infecting Sparus aurata. Number (average + SEM) of goblet cells positive $(\mathrm{GC}+$ ) for neutral (NEU), acidic (ACID) and carboxylic (CAR) mucins and sialic acid (SIAL) in the intestinal sections with no infection either from control $(\mathrm{C})$ or recipient (R) fish (NON), or low (LO) or high (HI) intensity of infection in R fish. Data from both diet groups and the 3 intestinal sections have been combined. Within each type of carbohydrate residue, different letters indicate statistically significant differences $(\mathrm{p}<$ 0.05). Spearman correlation coefficients $\left(\mathrm{r}_{\mathrm{S}}\right)$ and $\mathrm{p}$-values are indicated below for each carbohydrate

there is almost no information on the specific effect of diet composition on mucin pattern in the intestine of fish, and most studies are focused on the effects on intestine morphometry (Escaffre et al. 2007), intestinal fatty acid uptake (Geurden et al. 2009) and digestive enzymes (Santigosa et al. 2008, Silva et al. 2010). The only remarkable findings are the increased number of cells secreting acidic mucins, associated with reduced gut bacterial translocation and improved resistance to Vibrio alginolyticus in European sea bass Dicentrarchus labrax fed with mannan oligosaccharides (MOS) (Torrecillas et al. 2007, 2011a,b). In other animal models, feeding an enzyme-supplemented diet led to changes in the mucin composition and carbohydrate expression of GC glycoconjugates, which were associated with a reduction in intestinal viscosity and decreased numbers of the bacteria Campylobacter jejuni in chicks (Fernández et al. 2000). However, broiler chickens receiving a plant-protein-based feed had significantly less intestinal colonization with this bacterium (Udayamputhoor et al. 2003). Weaned piglets fed a carboxymethylcellulose enriched diet showed an increase in their ileal GC, mucin production and intestinal content viscosity, suggesting an improved protection against pathogens in the digestive tract (Piel et al. 2005). In the present study, there was no such stimulatory effect of the 66VO diet on GC in C fish, but rather the opposite effect was found. In any case, changes in digesta viscosity and their possible lubricant, digestive or protective effects remain to be studied in gilthead sea bream. Other possible changes in the gut physiology induced by the 66VO diet also merit further study, similar to those already shown in trout fed vegetable oil-based diets, which displayed a higher paracellular leakage in the intestinal epithelium than fish fed the control diet (Geurden et al. 2009).

At the same time, the infection with Enteromyxum leei produced a significant decrease of GC+ for all the stains applied and for sialic acid at the apical part of enterocytes at PI, the target site of the parasite. The effect of the infection was also detected in FO fish in the AI for neutral mucins and for sialic acid in the BB of E-infected fish, and in the MI for neutral, acidic mucins and sialic acid in GC. In the affected intestinal areas, GC were not only less numerous but also smaller, and were even absent in heavily parasitised areas of the PI. This was also observed by Fleurance et al. (2008) in gilthead sea bream and turbot Psetta maxima with advanced E. scophthalmi infections, whereas an increase in GC occurred in mild infections (Bermúdez et al. 2009). Previous studies have shown that prevalence and intensity of infection were higher in the $66 \mathrm{VO}$ group than the FO one, with a higher percentage of fish harbouring the parasite in the entire intestinal tract and a faster establishment of the parasite (Estensoro et al. 2011a). This is in agreement with the fact that the lowest values of GC were mostly registered in early infected $66 \mathrm{VO}$ fish in the PI and with the observed negative correlation between the intensity of infection and the number of GC with neutral, acidic and carboxylic mucins and sialic acid. Therefore, we can conclude that as time post-infection passed, the intensity of infection increased, the number of infected intestinal sections increased and the number of GC decreased.

Stimulation of the production of intestinal mucins has been widely shown for some nematode (Karlsson et al. 2000, Else 2005, Patel et al. 2009) and bacterial (Bergstrom et al. 2008) infections in mammalian models. Hyperplasia and hypertrophy of GC were evident in some enteric helminthiasis in brown trout Salmo trutta, with changes in the composition of the mucus and a significant increase in the number of 
GC staining positively for acid glycoconjugates, particularly close to the site of attachment (Bosi et al. 2005, Dezfuli et al. 2010). The number of GC was also raised in parasitised segments of eel Anguilla anguilla digestive tract, with an increase in the number of acid mucin-secreting cells (Dezfuli et al. 1997). Such increases are believed to contribute to the expulsion of enteric helminthes. However, the opposite GC depletion phenotype observed in Enteromyxum leei-infected fish could be due to the death or functional alteration of this cell type and implies a reduction of mucins released to the glycocalyx. The direct histopathological damage invoked by the myxosporean, which ends up occupying most of the mucosal intestinal surface, could explain such depletion. This GC reduction has also been reported in Echinostoma caproni infections (Fujino \& Fried 1993) and in clinically important enteric pathogens, such as Shigella (Steinberg et al. 1975, Sachdev et al. 1993), Campylobacter (Lambert et al. 1979) and Citrobacter rodentium (Bergstrom et al. 2008).

Comparisons are difficult since Enteromyxum leei dwells in the paracelullar space of the intestinal epithelium and the above cited cases refer to pathogens inhabiting the intestinal lumen or attached to the epithelial surface. In any case, in Citrobacter rodentium, depletion of mucus-containing GC correlates with peak bacterial colonization, as happens in the current fish-parasite model with the highest intensity of infection. The biological consequences of the functional modulation of GC are unclear. Downregulation of genes controlling GC-derived mucins could compromise the host defence when an animal is challenged with a bacterial pathogen. However, reducing mucin production might be important for reducing energy sources for pathogenic bacteria that use carbohydrate-laden mucins as a food source (Bergstrom et al. 2008). In fact, the glycosylation pattern of isolated intestinal mucus was changed in gilthead sea bream parasitised by E. leei and bacterial adhesion to it was reduced (Estensoro et al. 2011b). Further studies should determine whether changes in the intestinal bacterial population occur in E. leeiparasitised gilthead sea bream.

GC depletion in some enteropathogenic bacteria can also be mediated by components of the host immune system, such as some pro-inflammatory cytokines and T-cells (Arnold et al. 1993, Bergstrom et al. 2008, Linden et al. 2008). The observed slight decrease in the number of GC in non-infected sections of fish that harbour the parasite in other sections could suggest certain immune modulation. In Enteromyxum leei chronic infections, several immune factors have been shown to be modulated. IL- $1 \beta$ and TNF- $\alpha$ expression were depleted in the intestine and some serum innate factors were significantly decreased in $\mathrm{R}$ fish (Sitjà-Bobadilla et al. 2008, Estensoro et al. 2011a), whereas others such as the respiratory burst in circulating leukocytes (Estensoro et al. 2011a) or the number of immunoglobin M (IgM) positive cells in the intestine (Estensoro et al. 2011c) were increased. Furthermore, in a global molecular profiling of E. leeiparasitised gilthead sea bream, a marked down-regulation of the host immune system was detected (Davey et al. 2011). This was suggested to be a mechanism of immune evasion, as described for other fish and mammalian parasites (see Sitjà-Bobadilla et al. 2008), but further studies are needed to determine the possible connection between such immunodepresion and GC depletion.

There were no significant differences in the number of GC for most of the stains applied among the 3 intestinal sections in $\mathrm{C}$ fish, regardless of the diet, except for sulphated mucins and sialic acid of C$66 \mathrm{VO}$ fish, which had lower values in the AI than in the MI and PI. Neutral and acidic mucins were common in GC, and carboxyilic mucins were the most abundant among acidic ones, followed by mixed and sulphated mucins. Among acidic mucins, a size gradient was observed in GC, in which carboxylicpositive GC were larger than mixed ones and sulphated the smallest ones. Generally, the mucin type in intestinal GC seems to be highly specific to each teleost species. Thus, in shi drum Umbrina cirrosa, GC are filled mainly with sulphated mucins (Pedini et al. 2001), whereas in common dentex Dentex dentex neutral mucosubstances dominate in the AI (Carrassón et al. 2006). In turbot, neutral mucins also dominate in the digestive tract and acidic mucins are not present (Redondo \& Alvarez-Pellitero 2010a). The most common observation is that acidic and neutral mucins dominate and few acid mucopolysaccharides possess sulphate groups, while the majority are carboxylic, as in the current study (Scocco et al. 1997, Domeneghini et al. 1998, 2005, Fiertak \& Kilarski 2002, Park et al. 2003, Leknes 2010). The coexistence of neutral and acid glycoconjugates probably reflects different ages or stages of differentiation for GC (Elbal \& Agulleiro 1986, Murray et al. 1996, Leknes 2010). The same hypothesis could be applied for the different types of acidic mucins found in GC in the present study, and GC containing mixed carboxylicsulphated mucins could be a transient stage from carboxylic to sulphated or vice versa. However, such results may also suggest a true cellular heterogeneity in the population of GC (see Leknes 2010). 
In conclusion, changes in mucin composition and GC abundance in anterior and middle sections of the intestine of gilthead sea bream fed the 66VO diet appear to be one of the factors that make this diet as a predisposing cause that worsens the course of the disease when fish are exposed to Enteromyxum leei, the precipitating cause. These results together with the recent finding that some lectins inhibit the attachment and invasion of E. scophthalmi stages to the intestinal epithelium of turbot (Redondo \& Alvarez-Pellitero 2010b) open the door to the development of diets potentially capable of inducing mucin changes of fish intestine that avoid parasite adhesion and penetration, and therefore could contribute to the control of enteromyxosis. In addition, future studies should focus on the expression of intestinal mucin genes in response to parasites and on additional changes in gut physiology induced by dietary vegetable oils that could facilitate parasite invasion and proliferation, such as membrane fluidity and paracellular permeability.

Acknowledgements. This work was funded by the EU through projects AQUAMAX (FOOD-CT-2006-16249; Sustainable Aquafeeds to Maximise the Health Benefits of Farmed Fish for Consumers) and ARRAINA (KBBE-2011288925; Advanced Research Initiatives for Nutrition \& Aquaculture), and by the Spanish Ministry of Science and Innovation (MICINN) through the project AGL2009-13282C02-01. Additional funding was obtained from the 'Generalitat Valenciana' (research grant PROMETEO 2010/006). I.E. received a Spanish PhD fellowship (FPI) from MICINN and B.S. was recipient of a JAE-intro fellowship from CSIC. The authors thank V. Descalzo, C. Ferrer, M. A. González and L. Benedito-Palos for technical assistance in fish maintenance and samplings, J. Montfort and L. Rodríguez for histological processing and T. Gil (JAE-intro fellow) for her contribution to digital counts.

\section{LITERATURE CITED}

APROMAR (La Asociación Empresarial de Productores de Cultivos Marinos de España) (2011) La acuicultura marina de peces en España. Accessed 15 Dec 2011 www. apromar.es/Informes/informe \% 202011/Informe-APRO MAR-2011.pdf

Arnold JW, Klimpel GR, Niesel DW (1993) Tumor Necrosis Factor (TNF $\alpha)$ regulates intestinal mucus production during salmonellosis. Cell Immunol 151:336-344

Benedito-Palos L, Saera-Vila A, Calduch-Giner JA, Kaushik S, Pérez-Sánchez J (2007) Combined replacement of fish meal and oil in practical diets for fast growing juveniles of gilthead sea bream (Sparus aurata L.): networking of systemic and local components of GH/IGF axis. Aquaculture 267:199-212

Benedito-Palos L, Navarro JC, Sitjà-Bobadilla A, Bell JG, Kaushik S, Pérez-Sánchez J (2008) High levels of vegetable oils in plant protein-rich diets fed to gilthead sea bream (Sparus aurata L.): growth performance, muscle fatty acid profiles and histological alterations of target tissues. Br J Nutr 100:992-1003

Benedito-Palos L, Navarro JC, Bermejo-Nogales A, SaeraVila A, Kaushik S, Pérez-Sánchez J (2009) The time course of fish oil wash-out follows a simple dilution model in gilthead sea bream (Sparus aurata L.) fed graded levels of vegetable oils. Aquaculture 288:98-105

Bergstrom KSB, Guttman JA, Rumi M, Ma C and others (2008) Modulation of intestinal goblet cell function during infection by an attaching and effacing bacterial pathogen. Infect Immun 76:796-811

Bermúdez R, Faílde LD, Losada AP, Redondo MJ, AlvarezPellitero P, Quiroga MI (2009) Morphopathological and ultrastructural studies on enteromyxosis of turbot (Psetta maxima L.). 14th Int Conf Eur Assoc Fish Path. HALAMA, Prague, p 17

Bosi G, Arrighi S, Di Giancamillo A, Domeneghini C (2005) Histochemistry of glycoconjugates in mucous cells of Salmo trutta uninfected and naturally parasitized with intestinal helminths. Dis Aquat Org 64:45-51

Carrassón M, Grau A, Dopazo LR, Crespo S (2006) A histological, histochemical and ultrastructural study of the digestive tract of Dentex dentex (Pisces, Sparidae). Histol Histopathol 21:579-593

> Costello MJ (2009) The global economic cost of sea lice to the salmonid farming industry. J Fish Dis 32:115-118

$>$ Davey GC, Calduch-Giner JA, Houeix B, Talbot A, SitjàBobadillac A, Prunet P, Pérez-Sánchez J, Cairns MT (2011) Molecular profiling of the gilthead sea bream (Sparus aurata L.) response to chronic exposure to the myxosporean parasite Enteromyxum leei. Mol Immunol 48:2102-2112

Dezfuli BS, Manera M, Onestini S, Rossi R (1997) Histopathology of the alimentary canal of Anguilla anguilla L. associated with digenetic trematodes: a light and electron microscopic study. J Fish Dis 20:317-322

> Dezfuli BS, Pironi F, Campisi M, Shinn AP, Giari L (2010) The response of intestinal mucous cells to the presence of enteric helminths: their distribution, histochemistry and fine structure. J Fish Dis 33:481-488

> Dharmani P, Srivastava V, Kissoon-Singh V, Chadee K (2009) Role of intestinal mucins in innate host defense mechanisms against pathogens. J Innate Immun 1: 123-135

> Domeneghini C, Pannelli Straini R, Veggetti A (1998) Gut glycoconjugates in Sparus aurata L. (Pisces, Teleostei). A comparative histochemical study in larval and adult ages. Histol Histopathol 13:359-372

> Domeneghini C, Arrighi S, Radaelli G, Bosi G, Veggetti A (2005) Histochemical analysis of glycoconjugate secretion in the alimentary canal of Anguilla anguilla L. Acta Histochem 106:477-487

Elbal MT, Agulleiro B (1986) A histochemical and ultrastructural study of the gut of Sparus auratus (Teleostei). J Submicrosc Cytol Pathol 18:335-347

Else KJ (2005) Have gastrointestinal nematodes outwitted the immune system? Parasite Immunol 27:407-415

Escaffre AM, Kaushik S, Mambrini M (2007) Morphometric evaluation of changes in the digestive tract of rainbow trout (Oncorhynchus mykiss) due to fish meal replacement with soy protein concentrate. Aquaculture 273: $127-138$

Estensoro I, Benedito-Palos L, Palenzuela O, Kaushik S, Sitjà-Bobadilla A, Pérez-Sánchez J (2011a) The nutri- 
tional background of the host alters the disease course in a fish-myxosporean system. Vet Parasitol 175:141-150

Estensoro I, Jung-Schroers V, Steinhagen D, Sitjà-Bobadilla A (2011b) Glycoprotein changes in the intestinal mucus of gilthead sea bream Sparus aurata parasitized by Enteromyxum leei (Myxozoa). 14th Int Conf Eur Assoc Fish Path. Dalmacijapapir, Split, p 63

Estensoro I, Calduch-Giner JA, Kaushik S, Pérez-Sánchez J, Sitjà-Bobadilla A (2011c) Modulation of the gene expression of IgM and distribution of IgM+ cells by nutritional background and infection by Enteromyxum leei (Myxozoa) in gilthead sea bream (Sparus aurata). 14th Int Conf Eur Assoc Fish Path. Dalmacijapapir, Split, p 81

Ferguson JA, Koketsu W, Ninomiya I, Rossignol PA, Jacobson KC, Kent ML (2011) Mortality of coho salmon (Oncorhynchus kisutch) associated with burdens of multiple parasite species. Int J Parasitol 41:1197-1205

> Fernandez F, Sharma R, Hinton M, Bedford MR (2000) Diet influences the colonisation of Campylobacter jejuni and distribution of mucin carbohydrates in the chick intestinal tract. Cell Mol Life Sci 57:1793-1801

> Fiertak A, Kilarski WM (2002) Glycoconjugates of the intestinal goblet cells of four cyprinids. Cell Mol Life Sci 59: 1724-1733

> Fleurance R, Sauvegrain C, Marques A, Le Breton A, Guereaud C, Cherel Y, Wyers M (2008) Histopathological changes caused by Enteromyxum leei infection in farmed sea bream Sparus aurata. Dis Aquat Org 79: $219-228$

Fujino T, Fried B (1993) Echinostoma caproni and E. trivolvis alter the binding of glycoconjugates in the intestinal mucosa of $\mathrm{C} 3 \mathrm{H}$ mice as determined by lectin histochemistry. J Helminthol 67:179-188

Gendler SJ, Spicer AP (1995) Epithelial mucin genes. Annu Rev Physiol 57:607-634

Geurden I, Jutfelt F, Olsen RE, Sundell KS (2009) A vegetable oil feeding history affects digestibility and intestinal fatty acid uptake in juvenile rainbow trout Onchorhynchus mykiss. Comp Biochem Physiol A 152:552-559

> Harikrishnan R, Balasundaram C, Heo MS (2011) Impact of plant products on innate and adaptive immune system of cultured finfish and shellfish. Aquaculture 317:1-15

Karlsson NG, Olson FJ, Jovall PÅ, Andersch Y, Enerbäck L, Hansson GC (2000) Identification of transient glycosylation alterations of sialylated mucin oligosaccharides during infection by the rat intestinal parasite Nippostrongylus brasiliensis. Biochem J 350:805-814

Kent ML, Margolis L, Whitaker DJ, Hoskins GE, McDonald TE (1994) Review of Myxosporea of importance in salmonid fisheries and aquaculture in British Columbia. Folia Parasitol 41:27-37

Lambert ME, Schofield PF, Ironside AG, Mandal BK (1979) Campylobacter colitis. BMJ 1:857-859

Leknes IL (2010) Histochemical study on the intestine goblet cells in cichlid and poecilid species (Teleostei). Tissue Cell 42:61-64

Leknes IL (2011) Mucus cells in the digestive tract in prenatal platyfish larvae (Poeciliidae, Teleostei). Anat Histol Embryol 40:375-378

> Lima dos Santos CAM, Howgate P (2011) Fishborne zoonotic parasites and aquaculture: a review. Aquaculture 318:253-261

Linden SK, Sutton P, Karlsson NG, Korolik V, McGuckin MA (2008) Mucins in the mucosal barrier to infection. Mucosal Immunol 1:183-197
Maruyama H, Yabu Y, Yoshida A, Nawa Y, Ohta N (2000) A role of mast cell glycosaminoglycans for the immunological expulsion of intestinal nematode, Strongyloides venezuelensis. J Immunol 164:3749-3754

- Maruyama H, Hirabayashi Y, El-Malky M, Okamura S and others (2002) Strongyloides venezuelensis: longitudinal distribution of adult worms in the host intestine is influenced by mucosal sulfated carbohydrates. Exp Parasitol 100:179-185

> McCracken VJ, Lorenz RG (2001) The gastrointestinal ecosystem: a precarious alliance among epithelium, immunity and microbiota. Cell Microbiol 3:1-11

> Mennerat A, Nilsen F, Ebert D, Skorping A (2010) Intensive farming: evolutionary implications for parasites and pathogens. Evol Biol 37:59-67

Moncada DM, Kammanadiminti SJ, Chadee K (2003) Mucin and toll-like receptors in host defense against intestinal parasites. Trends Parasitol 19:305-311

Moran JDW, Whitaker DJ, Kent ML (1999) A review of the myxosporean genus Kudoa Meglitsch, 1947, and its impact on the international aquaculture industry and commercial fisheries. Aquaculture 172:163-196

> Murray HM, Wright GM, Goff GP (1996) A comparative histological and histochemical study of the post-gastric alimentary canal from three species of pleuronectid, the Atlantic halibut, the yellowtail flounder and the winter flounder. J Fish Biol 48:187-206

> Okamura B, Feist SW (2011) Emerging diseases in freshwater systems. Freshw Biol 56:627-637

Palenzuela O (2006) Myxozoan infections in Mediterranean mariculture. Parassitologia 48:27-29

Palenzuela O, Bartholomew JL (2002) Molecular tools for the diagnosis of Ceratomyxa shasta (Myxozoa). In: Cunningham CO (ed) Molecular diagnosis of salmonid diseases. Kluwer Academic Publishers, Dordrecht, p 285-298

Parillo F, Fagioli O, Ceccarelli P (2002) Glucidic determinants expressed by the digestive apparatus of Umbrina cirrosa (L.) fries as revealed by lectin histochemistry. Acta Histochem 104:209-215

> Park JY, Kim IS, Kim SY (2003) Structure and mucous histochemistry of the intestinal respiratory tract of the mud loach, Misgurnus anguillicaudatus (Cantor). J Appl Ichthyology 19:215-219

Patel N, Kreider T, Urban JF, Gause WC (2009) Characterisation of effector mechanisms at the host:parasite interface during the immune response to tissue-dwelling intestinal nematode parasites. Int J Parasitol 39:13-21

Pedini V, Scocco P, Radaelli G, Fagioli O, Ceccarelli P (2001) Carbohydrate histochemistry of the alimentary canal of the shi drum, Umbrina cirrosa L. Anat Histol Embryol 30: 345-349

Perez-Vilar J, Hill RL (1999) The structure and assembly of secreted mucins. J Biol Chem 274:31751-31754

Piel C, Montagne L, Sève B, Lallès JP (2005) Increasing digesta viscosity using carboxymethylcellulose in weaned piglets stimulates ileal goblet cell numbers and maturation. J Nutr 135:86-91

> Redondo MJ, Alvarez-Pellitero P (2009) Lectinhistochemical detection of terminal carbohydrate residues in the enteric myxozoan Enteromyxum leei parasitizing gilthead seabream Sparus aurata (Pisces: Teleostei): a study using light and transmission electron microscopy. Folia Parasitol 56:259-267

Redondo MJ, Alvarez-Pellitero P (2010a) Carbohydrate patterns in the digestive tract of Sparus aurata L. and Psetta 
maxima (L.) (Teleostei) parasitized by Enteromyxum leei and E. scophthalmi (Myxozoa). Parasitol Int 59:445-453

Redondo MJ, Alvarez-Pellitero P (2010b) The effect of lectins on the attachment and invasion of Enteromyxum scophthalmi (Myxozoa) in turbot (Psetta maxima L.) intestinal epithelium in vitro. Exp Parasitol 126:577-581

Redondo MJ, Cortadellas N, Palenzuela O, Alvarez-Pellitero P (2008) Detection of carbohydrate terminals in the enteric parasite Enteromyxum scophthalmi (Myxozoa) and possible interactions with its fish host Psetta maxima. Parasitol Res 102:1257-1267

Rombout JHMW, Abelli L, Picchietti S, Scapigliati G, Kiron V (2011) Teleost intestinal immunology. Fish Shellfish Immunol 31:616-626

Sachdev HP, Chadha V, Malhotra V, Verghese A, Puri RK (1993) Rectal histopathology in endemic Shigella and Salmonella diarrhea. J Pediatr Gastroenterol Nutr 16: 33-38

Saera-Vila A, Benedito-Palos L, Sitjà-Bobadilla A, NácherMestre J, Serrano R, Kaushik S, Pérez-Sánchez J (2009) Assessment of the health and antioxidant trade-off in gilthead sea bream (Sparus aurata L.) fed alternative diets with low levels of contaminants. Aquaculture 296: 87-95

Santigosa E, Sánchez J, Médale F, Kaushik S, Pérez-Sánchez J, Gallardo MA (2008) Modifications of digestive enzymes in trout (Oncorhynchus mykiss) and sea bream (Sparus aurata) in response to dietary fish meal replacement by plant protein sources. Aquaculture 282:68-74

Sarasquete C, Gisbert E, Ribeiro L, Vieira L, Dinis MT (2001) Glycoconjugates in epidermal, branchial and digestive mucous cells and gastric glands of gilthead sea bream, Sparus aurata, Senegal sole, Solea senegalensis, and Siberian sturgeon, Acipenser baeri development. Eur J Histochem 45:267-278

Scocco P, Menghi G, Ceccarelli P (1997) Histochemical differentiation of glycoconjugates occurring in the tilapine intestine. J Fish Biol 51:848-857

Silva FCP, Nicoli JR, Zambonino-Infante JL, Le Gall MM, Kaushik S, Gatesoupe FJJ (2010) Influence of partial substitution of dietary fish meal on the activity of digestive enzymes in the intestinal brush border membrane of gilthead sea bream, Sparus aurata and goldfish, Carassius auratus. Aquaculture 306:233-237

Sitjà-Bobadilla A, Diamant A, Palenzuela O, Alvarez-Pellitero P (2007) Effect of host factors and experimental conditions on the horizontal transmission of Enteromyxum leei (Myxozoa) to gilthead sea bream, Sparus aurata L., and European sea bass, Dicentrarchus labrax (L.). J Fish Dis 30:243-250

Sitjà-Bobadilla A, Calduch-Giner J, Saera-Vila A, Palen-

Editorial responsibility: Dieter Steinhagen,

Hannover, Germany zuela O, Alvarez-Pellitero P, Pérez-Sánchez J (2008) Chronic exposure to the parasite Enteromyxum leei (Myxozoa: Myxosporea) modulates the immune response and the expression of growth, redox and immune relevant genes in gilthead sea bream, Sparus aurata L. Fish Shellfish Immunol 24:610-619

Smith LS (1989) Digestive functions in teleost fishes. In: Halver JE (ed) Fish nutrition, 2nd edn. Academic Press, San Diego, CA, p 331-421

> Soffientino B, Gómez-Chiarri M, Specker J (2006) Developmental changes in stomach, intestine, and skin glycoconjugates in summer flounder (Paralichthys dentatus): a lectin histochemical study. Aquaculture 253:680-687

> Steinberg SE, Banwell JG, Yardley JH, Keusch GT, Hendrix TR (1975) Comparison of secretory and histological effects of shigella and cholera enterotoxins in rabbit jejunum. Gastroenterology 68:309-317

> Stroband HWJ, van deer Meer H, Timmermans LPM (1979) Regional functional differentiation in the gut of the grasscarp, Ctenopharyngodon idella (Val.). Histochemistry 64:235-249

- Tacchi L, Bickerdike R, Douglas A, Secombes CJ, Martin SAM (2011) Transcriptomic responses to functional feeds in Atlantic salmon (Salmo salar). Fish Shellfish Immunol 31:704-715

Tacon AGJ, Metian M (2008) Global overview on the use of fish meal and fish oil in industrially compounded aquafeeds: trends and future prospects. Aquaculture 285:146-158

Torrecillas S, Makol A, Caballero MJ, Montero D and others (2007) Immune stimulation and improved infection resistance in European sea bass (Dicentrarchus labrax) fed mannan oligosaccharides. Fish Shellfish Immunol 23: 969-981

> Torrecillas S, Makol A, Caballero MJ, Montero D, Ginés R, Sweetman J, Izquierdo MS (2011a) Improved feed utilization, intestinal mucus production and immune parameters in sea bass (Dicentrarchus labrax) fed mannan oligosaccharides (MOS). Aquacult Nutr 17:223-233

Torrecillas S, Makol A, Benítez-Santana T, Caballero MJ, Montero D, Sweetman J, Izquierdo MS (2011b) Reduced gut bacterial translocation in European sea bass (Dicentrarchus labrax) fed mannan oligosaccharides (MOS). Fish Shellfish Immunol 30:674-681

> Udayamputhoor RS, Hariharan H, Van Lunen TA, Lewis PJ, Heaney S, Price L, Woodward D (2003) Effects of diet formulations containing proteins from different sources on intestinal colonization by Campylobacter jejuni in broiler chickens. Can J Vet Res 67:204-212

> Woo PTK (2003) Cryptobia (Trypanoplasma) salmositica and salmonid crytobiosis. J Fish Dis 26:627-646

Submitted: January 30, 2012; Accepted: May 18, 2012

Proofs received from author(s): July 27, 2012 